\title{
Communication between anesthesiologists, patients and the anesthesia team: a descriptive study of induction and emergence
}

\author{
[Communication entre anesthésiologistes, patients et équipe d'anesthésie : une \\ étude descriptive de l'induction et du retour à la conscience]
}

Andrew F. Smith MrCP (UK), FRCA, * Catherine Pope PhD, † Dawn Goodwin PhD, $\ddagger$ Maggie Mort PhD $\ddagger$

Purpose: Although the importance of communication skills in anesthetic practice is increasingly recognized, formal communication skills training has hitherto dealt only with limited aspects of this professional activity. We aimed to document and analyze the informally-learned communication that takes place between anesthesia personnel and patients at induction of and emergence from general anesthesia.

Methods: We adopted an ethnographic approach based principally on observation of anesthesia personnel at work in the operating theatres with subsequent analysis of observation transcripts.

Results: We noted three main styles of communication on induction, commonly combined in a single induction. In order of frequency, these were: (I) descriptive, where the anesthesiologists explained to the patient what he/she might expect to feel; (2) functional, which seemed designed to help anesthesiologists maintain physiological stability or assess the changing depth of anesthesia and (3) evocative, which referred to images or metaphors. Although the talk we have described is nominally directed at the patient, it also signifies to other members of the anesthetic team how induction is progressing. The team may also contribute to the communication behaviour depending on the context. Communication on emergence usually focused on establishing that the patient was awake.

Conclusion: Communication at induction and emergence tends to fall into specific patterns with different emphases but similar functions. This communication work is shared across the anesthetic team. Further work could usefully explore the relationship between communication styles and team performance or indicators of patient safety or well-being.
Objectif : L'importance de la communication est de plus en plus reconnue en anesthésie, mais la formation structurée sur le sujet n'a porté jusqu'ici que sur des aspects limités. Nous voulions documenter et analyser la communication apprise de façon informelle et qui a cours entre le personnel d'anesthésie et les patients au moment de l'induction et du retour à la conscience lors d'une anesthésie générale.

Méthode : Notre approche, ethnographique, était fondée sur l'observation du personnel au travail dans les blocs opératoires et sur l'analyse subséquente des observations transcrites.

Résultats: Lors de l'induction, nous avons noté trois principaux styles d'informations ordinairement combinés. En ordre de fréquences, la communication était: (I) descriptive, où les anesthésiologistes expliquaient au patient ce qu'il pouvait s'attendre à ressentir ; (2) fonctionnelle, elle semblait organisée pour aider les anesthésiologistes à maintenir la stabilité physiologique ou à éva luer la différence de profondeur de l'anesthésie et (3) évocatrice, elle faisait appel à des images et à des métaphores. La conversation décrite était en principe dirigée vers le patient, mais elle indiquait aussi aux autres membres de l'équipe comment l'induction se déroulait. Dans certains contextes, l'équipe pouvait aussi participer à la communication. Au réveil, la communication visait habituellement à démontrer que le patient était éveillé.

Conclusion : La communication lors de l'induction et du retour à la conscience tend vers des modèles spécifiques comportant des aspects dominants qui ont toutefois des fonctions similaires. $\mathrm{Ce}$ travail de communication est partagé par les membres de l'équipe d'anesthésie. II reste à explorer la relation entre les styles de communication et la performance de l'équipe ou les indicateurs de la sécurité ou du bien-être du patient.

From the Department of Anaesthesia, Royal Lancaster Infirmary, ${ }^{*}$ Lancaster; the School of Nursing and Midwifery, University of Southampton, $†$ Southampton; and the Institute for Health Research, Lancaster University, Lancaster, United Kingdom.

Address correspondence to : Pr. Andrew Smith, Department of Anaesthesia, Royal Lancaster Infirmary, Lancaster LAl 4RP, UK, Phone: (01524) 583517; Fax (01524) 583519; E-mail: Andrew.f.smith@mbht.nhs.uk

The project from which this work arose was funded by the United Kingdom NHS North West Regional R\&D Fund ("The problem of expertise in anesthesia", project no RDO 28/3/05). 
$\mathrm{E}$

FFECTIVE communication skills are required for the practice of anesthesia as they are for any branch of clinical medicine. Despite their importance in practice $^{1,2}$ and training ${ }^{3}$ published work tends to deal with formal, explicit teaching of specific skills for use between doctor and patient. ${ }^{4}$ What anesthesiologists say to their patients as they go to sleep and wake up again has never been studied, and does not feature in traditional textbook teaching on anesthesia, but seems instead to be learned as part of the informal "unofficial syllabus" of anesthetic knowledge. Further, the issue of how communication is shared between anesthesiologists and other members of the anesthetic team does not appear to have been explored. We aimed to document what is said both on induction and on emergence and explore its significance in practice.

\section{Methods}

The approval of the local Research Ethics Committees was granted for this study, and written informed consent obtained from patients being cared for by the anesthesiologists under observation. The study was conducted principally in a medium-sized district hospital in the North West of England, with shorter periods of observation at a university hospital in the South West of England. Access can be difficult for research such as we report in this study, and we chose these two sites for their willingness to participate. We adopted an ethnographic approach, grounded in detailed observation, ${ }^{5}$ followed by a series of in-depth interviews. Ethnography is often used for the in-depth study of complex phenomena within the social context they occur and, as in this study, typically combines a range of methodological techniques. ${ }^{6}$ The larger study from which these data are drawn aimed to explore the ways different types of knowledge are acquired and used in anesthetic practice, focused mainly on the operating theatre environment, and included observation of and interviews with anesthesiologists, operating department practitioners (ODPs) ${ }^{\mathrm{A}}$ and nurses working in the operating room (OR) and postanesthesia care unit (PACU). ${ }^{7}$ Operating sessions were purposively sampled to cover a range of different types of surgery and anesthetic practice and levels of anesthetic expertise. All OR staff were aware of the study. The anesthesiologists taking part all had the opportunity to decline to be involved either in the study as a whole or in indi-

\footnotetext{
A The operating department practitioner is a grade of theatre staff unique to the UK. Their two/three year training course prepares them for three aspects of theatre work: assisting the surgeon, assisting the anesthesiologist and working in the postanesthesia care unit.
}

vidual observation. The research fellow would confirm participation before each observation session.

Although in many ways the preoperative visit is the basis of the anesthesiologist - patient relationship, we limited ourselves to communication behaviour during induction and emergence as these are "significant moments" in the anesthetic process for all concerned and also involve the wider anesthetic team. Typically, observation started in the anesthetic room before the patient arrived and, in some but not all cases, continued until after the patient had been transferred to the PACU. Conversation between all those in the anesthetic room was recorded - patients, members of the anesthesia team, surgeons and others who entered the room during this time.

The researchers recorded, with note book and pencil, the events, talk and behaviour of the anesthesiologists and other anesthesia personnel under observation. They aimed to capture the complexity of anesthesia practice. Immediately after the observation session, these were expanded and annotated, then transcribed for analysis. The interviews we conducted were carried out on a purposively selected cross-section of anesthesia personnel - physicians, nurses and ODPs (a type of anesthesiologist's assistant unique to the UK, see footnote). The interviews aimed to capture data on how anesthetic knowledge in general is acquired and used.

The analysis was directed towards classifying the communication which occurred at induction and emergence and began with individual close readings and annotations of the observational transcripts by all members of the project team, looking for recurring patterns of talk, behaviour and interaction. These were subsumed into broader categories and themes. ${ }^{8}$ Discordant data - instances where observed or reported communication differed from the norm or was deemed to be inappropriate in some way - were noted especially. Such cases usually stand out in the analysis as they apparently contradict the emerging explanation of the phenomena under study. They help refine the analysis by bringing to the researchers' attention aspects which might otherwise have gone unnoticed in the body of unremarkable "routine" data.

Differences in communication between expert and inexperienced practitioners were also sought. These can be valuable when a phenomenon such as tacit knowledge in anesthesia is being studied, as this knowledge is often more easily visible when it is poorly developed or still being formed, as in the observation of trainees at work. Formal statistical power calculations are unusual in this type of research. Instead, the emphasis is on trying to produce an account of what is being observed that makes sense to the subjects being 
studied - to get "under the skin" of what is going on. This usually entails the in-depth analysis of smaller samples. ${ }^{8,9}$ However, it can be assumed that sufficient data have been collected when further analysis of new data yields no new categories or themes. ${ }^{9}$ To check the accuracy of our perceptions, some of the research participants were invited to take part in the analysis (respondent validation). ${ }^{10}$

\section{Results}

Approximately three observation periods were carried out per month over one year, yielding a total of 39 sessions comprising 133 hours of data. These are numbered accordingly in the extracts given below. At the time we made our observations, there were 12 consultant anesthesiologists in the department and ten trainees. We observed all the consultants at least once. Of the 31 observations in the OR of the primary site, 13 were of consultants working alone, 12 were consultant with a trainee and six were of trainees working alone. We observed the induction of general anesthesia on 54 occasions, and saw 31 patients emerge from anesthesia. This imbalance arose from the fact that the observers were primarily following the anesthesiologist, and many patients had been handed over to PACU personnel before emergence. We also have data from 21 interviews, though there were few data of relevance to the current paper. Illustrative quotes have been selected from this larger pool of data.

\section{Communication on induction}

We noted three main styles of communication during induction. These three categories arose from the data early in the analysis, suggesting that we reached data saturation readily. Communication which referred to images or metaphors was termed evocative; if no evocative features were present, but an attempt was made to describe to the patient what was happening, the communication was labelled descriptive; if neither of the above features was present, it was termed functional. A breakdown of these is shown in Table I. Of the four inductions where no communication was recorded, one was an inhalational induction of an infant, one patient had been sedated and the third was anesthetized after a difficult and ultimately unsuccessful attempt at epidural insertion.

\section{EVOCATIVE}

These seem intended to invoke reassuringly pleasant or familiar images. The effects of sedative or analgesic drugs given before induction are compared to those associated with drinking alcohol. Other calming metaphors are also referred to. For instance, even though
TABLE I Inductions: communication styles and experience of anesthesiologist $(\mathrm{n}=53)$

\begin{tabular}{lll}
\hline & $\begin{array}{l}\text { Inductions by } \\
\text { consultant anesthesiologists } \\
(n=41)\end{array}$ & $\begin{array}{l}\text { Inductions by } \\
\text { trainees } \\
(n=10)\end{array}$ \\
\hline $\begin{array}{l}\text { Functional } \\
\text { Descriptive }\end{array}$ & 5 & 2 \\
Evocative & 13 & 6 \\
No induction talk & 2 & 1 \\
Consultant and trainee worked together on two inductions. One \\
of these showed a descriptive pattern. No talk to the patient is \\
recorded during the other.
\end{tabular}

time "stands still" for the patient during anesthesia, anesthesiologists often refer to its continuing progress.

"OK young man (injects propofol) you're going to bave fantastic dreams... feel nice and warm... you're on a golden sandy beach... wake up when it's all over." (soft, hypnotic voice). (Observation session 30, consultant anesthesiologist).

"Are you sitting comfortably? Then we'll begin". (Observation session 27, consultant anesthesiologist).

The second quote above was used to introduce the story in each edition of a British radio program for pre-school children called "Listen with Mother", which was popular in the third quarter of the 20th century.

\section{DESCRIPTIVE}

Here the anesthesiologist explains to the patient what he/she might expect to feel.

"I'm just going to give you something that will make you feel a little bit drowsy then we'll give you some oxygen to breathe and send you off to sleep". (Observation session 23, consultant anesthesiologist).

The anesthesiologist stands on the left hand side of the patient and continues to inject propofol into the drip tubing. The drug shows white in the tubing. A single snore is heard from the patient. "You'll start to feel very sleepy.". (Observation session 2, consultant anesthesiologist).

\section{FUNCTIONAL}

Here the talk is largely geared to assessing the depth of anesthesia or maintaining physiological stability (for instance, by inviting patients to take deep breaths of oxygen from a mask). 
The anesthesiologist tells her to keep the mask on. He attaches the propofol syringe to the cannula. "Keep your eyes open as long as you can." (He injects about $10 \mathrm{~mL}$ propofol). "Are you still with us?" The patient is talking - muffled. He injects another $5 \mathrm{~mL}$. "Open your eyes Margaret..." (Observation session 20, consultant anesthesiologist).

Communication during induction typically interweaves these different strands:

Anesthesiologist: "I'm sure this will give you a feeling of vodka....magic milk, coconut rum .....you're not allergic to anything?”

Patient: "No"

Anesthesiologist: "As you go off to sleep...oxygen over your face...”

Anesthetic assistant: "...magic milk... cold in your arm... take you off to dream land... think about something very pleasant..." (Observation session 31, junior resident).

Anesthesiologist: "I would like you to take some breaths of oxygen from the mask" $\mathrm{He}$ is standing at the head of the table, brings his left arm round into view holding the mask, he pauses (possibly to allow the patient to see it) then places the mask on the patient's face. At the same time with his right hand he injects a large syringe of white liquid (propofol, a commonly used anesthetic drug). He focuses on the big white syringe. "We will see you soon." (Observation session 9, senior resident).

Anesthesiologists thus tend to make use of highly individual communication "routines" on induction of anesthesia. Despite their ubiquity, nowhere in our study did we observe these being discussed or taught formally.

\section{Communication on emergence}

At the end of anesthesia, we observed anesthesia personnel talking loudly to patients, as if talking to the hard of hearing, and usually addressing them by name. Communication tended to fall into the functional category above, as it focused on establishing that the patient was awake - that is, responding to voice or command - and had regained vital physiological functions such as muscle strength, protective airway reflexes and breathing. We also observed some descriptive communication, where an attempt was made to reorientate or reassure the patient. In some cases, nurses in the PACU were the ones who spoke to the patient on emergence. The breakdown of styles and personnel is shown in Table II.
TABLE II Emergence: styles of communication and personnel $(n=31)$

\begin{tabular}{llll}
\hline & $\begin{array}{l}\text { Consultant anesthesiologists } \\
(n=15)\end{array}$ & $\begin{array}{l}\text { Trainees } \\
(n=10)\end{array}$ & $\begin{array}{l}\text { PACU nurses } \\
(n=6)\end{array}$ \\
\hline Functional & 12 & 5 & 5 \\
Descriptive & 2 & 4 & 1 \\
No talk & 1 & 1 & 0 \\
\hline
\end{tabular}

PACU $=$ postanesthesia care unit.

Anesthesiologist: "Hello my love" He looks at the patient's name band. "Hello. Open your eyes...good girl!” He removes the laryngeal mask airway. The nurse takes the patient into the PACU. (Observation session 3, consultant anesthesiologist)

Anesthesiologist (loudly, to the patient): "I'm just giving you some oxygen to breathe till you're properly awake." The bed is brought in, and the sheet and blanket from it are placed over the patient. "You're just coming round from the operation now..." (Observation session 7, consultant anesthesiologist).

Thus emergence communication shows a more restricted range of styles and tends to be less idiosyncratic. We find it somewhat striking, however, that it seems to be common both on induction and emergence to talk to adult patients with a tone of familiarity usually reserved for children.

\section{Appropriate and inappropriate communication}

Induction communication is designed to reassure the patient whilst also signalling to others that induction is taking place, thus helping to ensure that it is accomplished successfully. Without it, the smooth, predictable sequence of events can be disrupted.

"There have been a couple of other cases where I've felt uneasy really. In one particular instance, the anesthesiologist gave the anesthetic without warning the patient and the patient panicked. I felt uneasy then, I felt very uneasy because the patient sat bolt upright and started grabbing hold of her throat and I felt bad because I hadn't warned the patient. I thought the anesthesiologist was going to do it... the patient was scared stiff... if that was me I would bave quite a phobia about coming into theatres now." (Interview 11, ODP - for definition see footnote under "Methods" above).

Another case was described where a similar loss of continuity might have occurred, but the assistant realized sooner and was able to act to try to "repair" the situation. 
While we are waiting for the next patient, Brian (an ODP) talks to me in the corridor. He talks about what happened with the previous patient. He points out how the anesthesiologist set the propofol infusion going but didn't tell either him or the patient that she was going off to sleep, he just noticed the infusion going, so he quickly moved to the side of the patient to hold her steady (as she was lying on her side) and reassure her (notes recorded in theatre during observation session 32 ).

We observed one case (of urgent DC cardioversion on the coronary care unit) of inappropriate communication on the part of a nurse who would not normally be part of the anesthesia team.

Medical resident: "Charging to 200, stand clear, shocking to 200"

The patient now starts to make some noise. It is not like a whine or speech, more like a loud, verbal exhalation, "urgh")

Ward nurse: "Hello Patricia, we're just in the middle of the procedure" (loudly)

Anesthesiologist: "Shbh"

$\mathrm{He}$ injects again. (Observation session 27, consultant anesthesiologist)

Here, the ward nurse has mistaken the patient's grunting for return of consciousness and is attempting to reorientate her to what is happening. An experienced member of the anesthesia team would "read" the situation correctly. The anesthesiologist silences this interruption, whereas appropriate contributions by other members of the anesthesia team are usually welcomed.

\section{Discussion}

Our study describes how anesthesiologists talk to patients on induction of, and emergence from, general anesthesia. In qualitative research such as this, issues of representativeness in the sense of statistical significance are usually held to be less important than the production of a valid and accurate account which makes sense both to those who took part (and we presented emerging data to the anesthetic department concerned) and those in the same area of work (including the readers of this article). ${ }^{10}$ From our analysis and feedback from participants we feel we have achieved this.

The communication "routines" we have described are deeply embedded in anesthetic practice. We have observed that it is not so much what is said (though anesthesiologists appear to choose from a small number of possible phrases), but its timing and nature which are important. The interview extract above shows how uneasy an anesthesiologist's assistant felt when the communication was missing or "broken", especially as he was unable to "repair" it. The second excerpt refers to the fact that induction communication not only signals to all concerned that the patient is about to be anesthetized, ${ }^{11}$ but can be shared work for the whole anesthesia "team" - sometimes anesthesiologists' assistants will "fill in", especially if they find anesthesia being induced without the appropriate communication from the anesthesiologist. Experienced personnel do this so smoothly and subconsciously that the collective expertise which makes it possible usually passes unnoticed. It is of course possible that some of our data show less communication because the whole process of induction had previously been discussed at the preoperative visit. When people who do not understand the routines start to contribute, the lack of skill is obvious. Although the ward nurse's attempts to talk to the patient undergoing cardioversion in the excerpt from observation 27 may reflect familiarity with dealing with sedated patients on critical care units, our reading is that she mistook the patient's grunting as a sign of returning consciousness rather than a response to the DC shock. Calling the patient's name, and attempting to reorientate her would be typical of emergence communication and is abruptly silenced by the anesthesiologist.

The style of communication can be said to capture the implied relationship between anesthesiologist and patient, and this varies from the style of an adult talking to a child to more functional or metaphorical ${ }^{12}$ material. The words and tone adopted reveal much about the nature of this relationship. Consider for instance the contrast between "magic milk" -which brings to mind images of a parent tucking a child into bed for the night - and the simple "see you in an hour or so" which both focuses the patient's attention on the future, after the operation, and also carries the informal, but more egalitarian air of two acquaintances arranging to meet up again shortly.

Expertise in anesthesia, in common with other fields, rests on the successful relationship between different forms of knowledge. There is "explicit" knowledge, which is capable of being written down, codified and communicated in textbooks and journals and set out in examination syllabuses. There is also "tacit" knowledge, defined as "knowledge that has not been (and perhaps cannot be) formulated explicitly and therefore cannot be stored or transferred entirely by impersonal means"13 It is typically acquired via demonstration followed by practice. Our related work ${ }^{7,14}$ has begun to unravel the relationship between formal 
knowledge and the knowledge born of experience in expert anesthetic practice. Formal training in communication skills is to be welcomed but we would suggest that a substantial amount of teaching and learning of these skills goes on almost unrecognized during the interactions we have documented. Indeed, formal training programs may, by definition, be inadequate to convey the sort of knowledge we have described. We have suggested that the use of observational methods, with transcript analysis and debriefing, would be one method of incorporating an awareness of such aspects of anesthetic expertise for trainees and experienced practitioners alike. ${ }^{15}$ A less intensive approach simply needs anesthesiologists to acknowledge the importance of such knowledge in their practice. Our experience suggests that they subsequently tend to bring out these aspects when teaching and when training others.

Future work might usefully explore the effect of different styles of communication on patient anxiety, patient satisfaction, anesthetic team performance and markers of patient safety. One point to bear in mind, however, would be that as many patients have some degree of amnesia for induction and emergence, whatever is said by the anesthesiologist during these periods may not affect outcome. However, it is clear that the orientation of anesthesiologists' communication styles varies, some being more attuned to patients' particular needs than others. Perhaps the most telling sign of the difference in perspective is the anesthesiologist's cheerful claim on emergence "It's all finished!" when as far as the patient is concerned, regaining consciousness is only the beginning.

\section{Acknowledgement}

We would like to thank all the anesthesia personnel who feature in the examples above and their patients for allowing us to carry out this work.

\section{References}

1 Smith AF, Shelly MP. Communication skills for anesthesiologists. Can J Anesth 1999; 46: 1082-8.

2 Kopp VJ, Shafer A. Anesthesiologists and perioperative communication. Anesthesiology 2000; 93: 548-55.

3 Royal College of Anaesthetists. The Certificate of Completion of Specialist Training (CCST) in Anaesthesia. Part I, General Principles: Appendix 2: 23-8. London: Royal College of Anesthesthetists, 2003 Available from URL; www.rcoa.ac.uk/docs/ ccstptied2.pdf (accessed 16 January 2004)

4 Harms C, Young JR, Amsler F, Zettler C, Scheidegger $D$, Kindler $C H$. Improving anaesthetists' communication skills. Anaesthesia 2004; 59: 166-72.

5 Atkinson P, Coffey A, Delamont S, Lofland J, Lofland
L. Handbook of Ethnography. London: Sage Publications; 2001.

6 Savage J. Ethnography and health care. BMJ 2000; 321: 1400-2.

7 Smith A, Goodwin D, Mort M, Pope C. Expertise in practice: an ethnographic study exploring acquisition and use of knowledge in anaesthesia. Br J Anaesth 2003; 91: 319-28.

8 Silverman D. Interpreting Qualitative Data: Methods for Analysing Talk, Text and Interaction, 2nd ed. London: Sage Publications; 2001.

9 Miles MB, Huberman AM. Qualitative Data Analysis. An Expanded Sourcebook, 2nd ed. Thousand Oaks, California: Sage Publications; 1994: 278-9.

10 Pope C, Ziebland S, Mays N. Analysing qualitative data. Br Med J 2000; 320: 114-6.

11 Hindmarsh J, Pilnick A. The tacit order of teamwork: collaboration and embodied conduct in anesthesia. Sociol Quart 2002; 43: 139-64.

12 Shafer A. Metaphor and anesthesia. Anesthesiology 1995; 83: 1331-42.

13 MacKenzie D, Spinardi G. Tacit knowledge, weapons design, and the uninvention of nuclear weapons. Am J Sociol 1995; 101: 44-99.

14 Smith AF, Mort M, Goodwin D, Pope C. Making monitoring 'work': human-machine interaction and patient safety in anaesthesia. Anaesthesia 2003; 58: 1070-8.

15 Pope C, Smith A, Goodwin D, Mort M. Passing on tacit knowledge in anaesthesia: a qualitative study. Med Educ 2003; 13: 650-55. 